Problems of quantum biochemistry

Quantum Biochemistry and Specific Interactions. By Z. Simon. Pp. 251. (Abacus: Tunbridge Wells, Kent, UK, 1976.) $£ 11.95$.

APPLYING the methods of quantum chemistry to problems in biochemistry is so fraught with difficulties that high levels of scepticism are required in addition to enthusiasm for the subject. Until very recently theoretical chemists were not notably successful in calculating properties of small isolated molecules let alone large molecules in aqueous solution or in even more complicated environments.

Over the past few years the problems of molecular physics have become tractable due to refinements of molecular orbital techniques and the power of computers. With the confidence gained from success with the isolated molecule, theoreticians are becoming more interested in biological problems; in particular conformational studies and comparisons of reactivity are proving valuable. Professor Simon's book, originally published in Romanian in 1973, was written before the advances of the past few years, but must have been almost out of date even then.

The molecular orbital technique described in the chapter which follows the introduction is almost totally de voted to $\pi$-electron Hückel theory; a final section on 'advanced methods' lists variants more likely to be referred to as 'crude' in current publications; and neither $a b$ initio nor PCILO approaches are mentioned. None of the many references cited is later than 1973 despite the fact that the work is described as a 'revised, up-dated translation'. It is an elaboration of the work of the Pullmans in their 1963 book on quantum biochemistry rather than the total revision which would be much welcomed.

Similarly, the chapter on intermolecular forces rests heavily on work by the Pullmans and Scheraga, which both groups would probably consider to have been superseded. Reactivities are discussed in terms of parameters deduced from $\pi$-electron calculations rather than the potential surfaces currently in vogue.

The specific interactions referred to in the title and an analysis of some recognition processes occupy the last two chapters of the book. Enzyme reactions, repressor-operator interactions and specificity in immune phenomena are all considered, but much more space is devoted to descriptions of the topics and to quantitative measures than to applications of quantum mechanical methods.

The strength of the book is its collection of facts and topics of biochemistry which remain as problems rather than a description of how they have been solved. The descriptive portion like the theory suffers from the time lag in appearance of the work, but it is impossible to read without feeling an urge to tackle some of the problems with more up-to-date methods.

The book is in no way an account of the state of the art but it is a valuable collection of topics and references more to be recommended to the seasoned campaigner than to the student.

Graham Richards

Graham Richards is a Lecturer in the Department of Physical Chemistry at the University of Oxford, UK.

\section{Whirlpool of aggression}

The Evolution and Chemistry of Aggression. By D. D. Thiessen. Pp. xviii+211. (Charles C. Thomas: Springfield, Illinois, 1976.)

THE first chapter of this book is entitled "The Evolution of Competitive Behavior". The other four are on gene organisation, endocrine control, chemical social signals, and the actions of drugs. There is a bibliography of about 300 entries, and a very brief subject index. The author's stated intention is to investigate aggression in relation to evolution and chemistry. "Unless otherwise noted", he writes, "aggression will refer to intermale aggression."

I read the first chapter in some bewilderment. "Aggression," we are told, "in one form or another, is as old as life itself." The first pages include passages on 'molecular aggression', competition between species, predator-prey interactions, and species diversification. There follows a section on "a move toward intraspecific competition" devoted largely to the unusual conduct of a species of sea anemone. There is then one on brain differentiation, in which there are references to 'competitive readjustment of brain size' and 'selection for neurological competence to deal with distance perception'.

Dr Thiessen evidently equates aggression with competition. "If an animal fails to fight", he tells us, "we too readily conclude that he is nonaggressive. . . Even an animal that does not fight . . . may still be highly competitive." In some passages competition seems to be thought of as equivalent to what goes on in the private sector. The biological principles that deal with competition are those of population genetics, but they are disregarded. Instead, we have tautologies: for example, "there is positive selection for those forms that optimize their use of space and commodities and negative selection for those forms that fail." Similarly, none of the recent critical reviews on natural selection in relation to behaviour, or on intolerant behaviour within species, are represented in the bibliography.

Dr Thiessen's chapter on his own speciality, the endocrine control of behaviour, summarises much interesting work, but again without a unifying theme. Among the many topics mentioned are sex reversal in fish and mammals, the disorganisation of sexual development by early treatment with hormones, the metabolism of the hypothalamus, hormones and social status, and human chromosome abnormalities. There is also a discussion of the behavioural changes that accompany the human menstrual cycle.

Dr Thiessen is not always uncritical. In this field the danger of inferring causal relationships from correlations is always with us. For example, violent prisoners have high plasma testosterone levels. Dr Thiessen remarks that the violence may not be due to the hormone: instead imprisonment could increase testosterone secretion. And on page 82 he utters an important warning: "specialised definitions of aggression involving violence and sexual assault may be more amenable to investigation than more generalised notions of aggression."

This principle could have been usefully applied to the chapter on drugs. "A survey of the literature", we learn, "indicates that almost all classes of drugs studied have been found to decrease, increase or not influence aggression." This is not surprising when we find, a few pages later, a list which includes "footshock aggression" (probably defensive postures induced by pain), "isolation aggression" (possibly a response to strangeness), "irritable aggression" due to brain injury, "aggression" induced by various drugs, and predatory behaviour.

The editor of the American Lecture Series, Dr I. N. Kugelmass, writes in his foreword: "What is aggression? It is life itself - a whirlpool in many ways. When once set agoing it spins on and on." As Australians say, too right.

S. A. Barnett

S. A. Barnett is Professor of Zoology at the Australian National University. Canberra. 